\title{
THE APPLICATION OF NONLINEAR CHANGE THEORY TO THE DEMISE OF SAAMBOU BANK
}

\author{
Christian Louis van Tonder \\ Department of Human Resource Management, University of Johannesburg
}

\begin{abstract}
Nonlinear change represents the latest in a series of change concepts that reflect a change in the complexion of organisational change itself. Nonlinear change theory provides an alternative and potentially useful framework from within which to view seemingly dramatic corporate failures. To test its utility value, an attempt is made to fit the sequence of primary events preceding the demise of Saambou Bank to a nonlinear change framework. This application of the theory suggests that some value can be derived from its use - in particular as it provides an extended temporal perspective and can potentially further illuminate the unfolding dynamics in such cases. The implications of nonlinear change theory are briefly discussed.
\end{abstract}

JEL L22

\section{1}

\section{Introduction: The notion of change}

The subject of organisational change was and still is a consistent preoccupation of philosophers, scholars and managers. It has similarly received more than its fair share of attention in the scientific literature, with more than a million publications on the subject recorded as early as 1995 (Van de Ven \& Poole, 1995) yet it continues to command substantial interest. One of the reasons for this may be the fact that more change practices turn out to be "unsuccessful" rather than "successful" (cf. Applebaum \& Wohl, 2000; Mariotti, 1998; Van Tonder, 2005a). Indeed, between 65 per cent and 75 per cent of change initiatives are deemed to be unsuccessful (Beer \& Nohria, 2000; Grint, 1998; Mourier \& Smith, 2001). At the same time the extant change literature, though extensive, is not considered to be particularly useful (Bamford \& Forrester, 2003), which suggests that change and organisational change are still far from being fully understood. Recent corporate history and in particular the demise of Barings Bank, Enron, Parmalat, Saambou, WorldCom and others, apart from being many other things, also constitutes "change for the worse" or "change-gone-wrong". These examples bear testimony to the often limited value of prevailing change knowledge. It appears as if the disastrous corporate change in these instances could not be circumvented or contained despite abundant knowledge and expertise on the subject. It is in these situations that complexity theory, and nonlinear change theory in particular, offers a framework that could shed more light on the dynamics in these cases.

Against this context the purpose of this paper is to briefly introduce the theoretical fundamentals of nonlinear organisational change (nonlinear change theory) and to explore its usefulness as an analysis frame in the case of the former Saambou bank, which, from the perspective of the public, appeared to be quite sudden. The discussion commences with an outline of nonlinear change theory, which is then used as a template for viewing the dramatic change that occurred in the case organisation (Saambou Bank). The paper concludes with a brief discussion of some of the implications that arise from the application of nonlinear change theory to the case organisation. 
For the purpose of this paper, change is viewed as a dynamic, time-bound, and non-discrete process evident in an empirical difference over time in the state and / or condition of the organisation (Van Tonder, 2004a). However, while the implicit structure of change is probably consistent, the pace and scope of change within organisations itself appear to be accelerating (Burnes, 2003; Schabracq \& Cooper, 2000; Vakola, Tsaousis \& Nikolaou, 2004). In this regard it has been argued that the phenomenon of organisational change when viewed from an expanded time perspective appears to have evolved from predictable, linear or deterministic change through more dynamic, adaptive or equilibrium-based change, to complex or nonlinear change (Van Tonder, 2004b). This progression represents a substantial shift in the conceptualisation of organisational change. From essentially a onedimensional rational, linear, and predictable notion of change, sentiment has now evolved to one that considers change to be multidimensional, often irrational, spurious, significant in its impact and largely unpredictable (Van Tonder, 2004b). This happened in concert with similar evolutionary shifts in the way that scholars viewed the organisation (as system) and its operating environment. Both these constructs have assumed a progressively more sophisticated and dynamic character (Van Tonder, 2004b). Systems views of the organisation for example capture this changing view of the operating context. The earlier notion of a closed system, for example, implied a largely passive, insignificant and manipulable environment, whereas the progression through cybernetic, open and nonlinear systems views conveys an increasingly influential, turbulent and unpredictable operating context.

This evolutionary process was accompanied by the introduction of several "new" and progressively more sophisticated change concepts and typologies. To illustrate: consider the notion of evolutionary change which constituted the dominant view of change during the reign of classical management theorists (circa 1930s) when a predominantly closed

systems view of the operating context prevailed. When turbulence became a salient feature of the competitive environment, evolutionary change was supplemented by revolutionary change (cf. Greiner, 1972; 1998). The subsequent emergence of the punctuated equilibrium view of organisational change (an inheritance from evolutionary biology) accorded equal "living space" to both evolutionary and revolutionary change types (cf. Tushmann \& Romanelli, 1985; Gersick, 1991), while contemporary notions of nonlinear change represent a substantially more evolved and sophisticated account of the interdependence and interaction of these two coexisting change types (cf. Van Tonder, 2004c).

To date a bewildering range of change and organisational change typologies have surfaced, but these are hardly noticed and seldom acknowledged in managerial circles. So for example we note that Lewin's (1951) initial notion of change as a sequence of activities that emanate from disturbances in the stable force field that surrounds the organisation (or object, situation, or person) has since been superseded by, among other, concepts such as first and second-order change (Bartunek, 1993; Bartunek \& Moch, 1987; Watzlawick, Weakland \& Fisch, 1974), Alpha, Beta, Gamma change (Golembiewski, Billingsley \& Yeager, 1976), transformation (Levy \& Merry, 1986), evolutionary and revolutionary change (cf. Greiner, 1972; Tushman \& Romanelli, 1985; Gersick, 1991), Type I and Type II change (Van Tonder, 1999; 2004d) and nonlinear dynamics, "chaos" (cf. Thiétart \& Forgues, 1995) or chaotic change, complex change or catastrophic change (Van Tonder, 2004c; 2004d) ${ }^{1}$. The latter not only constitutes the most recent addition to the change lexicon, but it also represents the most evolved characterisation of organisational change to date. The notion of nonlinear change consequently warrants further attention.

2

\section{Nonlinear change theory}

Consistent with the proliferation of alternative concepts of change, different expressions of 
nonlinear change have randomly surfaced in the literature e.g. complex, Type II, catastrophic, dissipative, chaotic, and fatal chaotic change. They are, however, largely employed as synonyms and, with few exceptions, are in need of more precise definition. The phrase nonlinear change is used here conveniently as a collective phrase to encapsulate the different change concepts which essentially denote an "extreme" type of change. The bulk of the literature suggests that nonlinear change is change characterised by the disproportionate magnitude of the change trigger (insignificantly small) and the change consequence (unpredictably large) and hence nonlinearity. This articulation is however too lean to do justice to the nature and dynamics of this form of change. Nonlinear change in this discussion will encapsulate for example:

- chaotic change - "a rapidly unfolding form of comprehensive change, triggered by an insignificant or small incident, with unpredictably catastrophic outcomes" (Van Tonder, 2004c: 230), and

- Type II change - "a major, disruptive, unpredictable, paradigm altering and system-wide change which has a very sudden onset and escalates rapidly to a point where it is perceived as beyond the control of the system" (Van Tonder, 1999: 51).

These two types of change suggest several dimensions of change beyond that of a disproportionate trigger-outcome relationship. Change can, for example, be profiled in terms of the dimensions of time / duration (the pace of onset, unfolding and dissipation), the scope of reach / impact, control over the change (its susceptibility to influence), intensity, impact / ramifications, predictability, and the nature and source of energy that sustains the change (Van Tonder, 2004d). Nonlinear change (types) invariably characterises the extremities of these dimensions... it is rapid in its onset, unfolding, and dissipation; extensive in scope / reach; uncontrollable; extremely intense; significant if not catastrophic in its impact; unpredictable (nonlinear), and draws on self-generating and self-sustaining energy sources. Some variation on these dimensions is however conceivable as change is not discrete, and consequently some forms of nonlinear change may not be fatal or for that matter completely irreversible. Nonlinear change certainly is not a novel phenomenon, but nonetheless occurs infrequently. Its presence has been revealed in various domains such as volcanic eruptions, Tsunamis, earthquakes, heart attacks, seizures, random killing sprees, the outbreak of contagious diseases, riots and mob behaviour, stock exchange crashes, and, as we will argue, also in an organisational sense.

It is of course impossible to entertain a notion of nonlinear organisational change without implicitly assuming that organisations are nonlinear dynamical systems or, to be more precise, complex adaptive social systems (as many complex systems are not adaptive Pascale, 1999). It is in fact quite common to view organisations as complex or nonlinear dynamical systems (cf. Ashmos, Duchon \& McDaniel, 2000; Beeson \& Davis, 2000; Dooley \& Van de Ven, 1999; Maguire \& McKelvey, 1999; Styhre, 2002; Sullivan, 1999).

Nonlinear change is characteristic of complex nonlinear systems and a consequence of the systems condition of complexity. Complexity, in a definitional sense, however has been difficult to pin down (Maguire \& McKelvey, 1999). To avoid being drawn into semantics, complexity is used here in its most frequently occurring form i.e. "descriptive complexity" which refers to that mixture of a significant number of variables within a setting or "field", a high degree of interdependence between them, as well as a high frequency of interaction among these variables. In an organisational sense it has been suggested that complexity commences when three or more variables are interdependent and interact on a consistent basis (Thiétart \& Forgues, 1995).

For the fact that change is informed by its context (Bolton \& Heap, 2002) it is important to acknowledge that a variety of nonlinear systems are in existence and hence a variety of nonlinear change concepts are conceivable. In broad terms these change forms are similar but at a finer level of discrimination will reflect variation which is associated with the dominant and distinctive features of the systemic contexts in which change unfolds. In this regard it is necessary to distinguish between complex and 
chaotic systems and consequently "complex" and "chaotic" change. Chaotic systems continuously change from one state to the next and do so in an unpredictable, continuous and rapid fashion. Complex systems on the other hand are only occasionally exposed to chaotic change dynamics and are able to exert some control over unanticipated environmental shocks. For this reason fairly "ordered" change types such as Type $\mathrm{I}^{2}$ or evolutionary change will be observed in complex systems, but never in chaotic systems. This ability to maintain a degree of stability when finding itself enveloped in highly complex circumstances is what essentially distinguishes the complex system from a chaotic system. In this regard Maguire and McKelvey (1999: 35) for example argued that few economic environments are chaotic (are more likely complex).

When characterised by extreme levels of complexity, it is said that the system finds itself on the edge of chaos - described as a border area between predictability and nonpredictability (Marion \& Bacon, 2000). Only a minute threshold separates stability and chaos in this transition zone. When such circumstances prevail complex systems are acutely vulnerable and only a very small trigger event is required to "push" the system into the domain of chaos and the onset of chaotic change. However, unlike chaotic systems, complex systems have the ability to consolidate and reintroduce stability during, or immediately after, (nonfatal) chaotic change.

Goerner (1994) further differentiates between conservative and dissipative nonlinear dynamic systems. The former consist of classical and quantum systems and essentially conserve energy while dissipative systems or structures (cf. Prigogene \& Stengers, 1984), which include organisations, are characterised by energy "dissipation" into the surrounding environment. Dissipation refers to the spontaneous and rapid movement of energy from high to low energy concentrations (i.e. across an energy differential). The theory of dissipation offers a useful account of why nonlinear change ensues and suggests that when energy build-up cannot be contained and the discrepancy between high and low concentrations reaches unbearable levels, chaotic change will follow (energy dissipation). In chaotic systems this form of nonlinear change will not only be chaotic but also catastrophic i.e. characterised by disorder and confusion on the one hand and devastating consequences on the other such as great destruction and/or suffering. In this instance the change is bound to be fatal. When a complex system momentarily transforms into a chaotic system, nonlinear change could be both chaotic and catastrophic but with a significantly diminished incidence of catastrophe. This is possible only because the system is capable of intervening and stabilising the change to a degree (for example the imposition of curatorship over a bank, following a "run" on deposits). In such instances the concept of fatality may be muted and a limited degree of reversibility of impact over time may be possible.

Nonlinear change is likely to occur when the condition of sufficient organisational complexity has been met. This normally signals a transformation of the system (organisation) from an open systems state to a complex systems state. Once within a complex systems state, a small triggering event is all that is required to transition the system to a chaotic systems state and bring about chaotic and catastrophic organisational change, whereafter it will revert back to a more stable open systems state. This change in the state of the organisation as system is at the centre of nonlinear change theory and the recurring pattern of cyclical order and disorder.

This order-disorder-order transition can be further disaggregated into three broad phases and with intermediate phase transitions which are illustrated in Figure 1. The first phase transition represents a shift from a situation of relative organisational stability and minimal complexity to a situation of complexity and fragile stability (the so-called edge-of-chaos). The second phase transition refers to the organisation's crossing over into the domain of chaos and its rapid descent into chaos, while the third phase transition represents the emergence of a new level of order and stability.

With reference to Figure 1, note that complexity arises when organisations find 


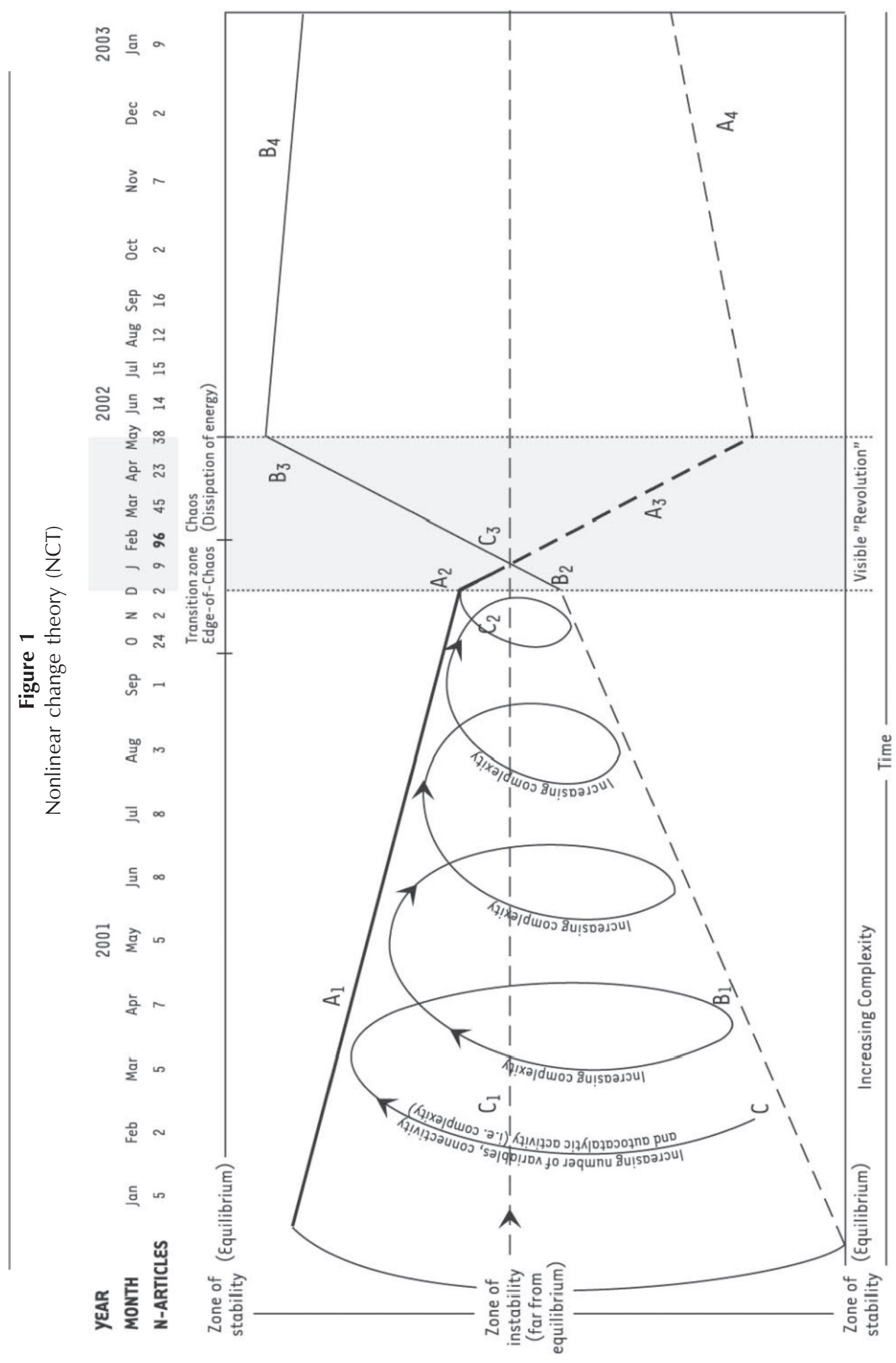


themselves located in dynamic settings where they are continuously subjected to powerful yet balanced counteracting forces for change. These forces exert pressure towards stability (refer A1, Figure 1), yet also exert pressure towards instability (B1). With pressure building up, the organisation is "pushed" to greater levels of complexity and into a threshold zone bordering on chaos (C2) referred to as the "far from equilibrium" zone and "the edge-of-chaos". In this domain the organisation is characterised by heightened tension and an intricate interdependence and a high degree of interaction among system components, and is exceedingly vulnerable to minute changes. If the organisation cannot contain the energy build-up and increasing energy differential in this threshold zone (maintain a state of balance), a very small, insignificant activity ("perturbation") can become a trigger event or breakpoint ("bifurcation" - refer C3, Figure 1). This trigger event will set a chain reaction in motion that culminates in the dramatic and most often catastrophic release of energy (i.e. nonlinear change). In Figure 1 this nonlinear change (also a phase transition) proceeds from $\mathrm{A} 2$ to $\mathrm{A} 3$ and $\mathrm{B} 2$ to $\mathrm{B} 3$ in a sudden, dramatic and discontinuous way. It may be non-fatal (chaotic change only) or fatal (chaotic and catastrophic). In complex organisational systems this chaotic change process is followed with the emergence of a new and higher level of order and stability (referred to as selforganisation) around new stabilising "attractors" e.g. new identity, culture and new inertia (Marion \& Bacon, 2000). If the organisation is incapable of making this "leap" to a new level of stability, catastrophic collapse follows and order and stability will then only emerge in the meta-aggregate (cf. Marion \& Bacon, 2000) or suprasystem such as an industry or national or international setting. In such cases the chaotic change is considered a fatal or catastrophic change.

Complexity theory holds that this newfound "order" is unlikely to endure and that counterbalanced forces for and against change (see A4 and B4) will gradually erode organisational stability and facilitate the development of increasingly complex conditions. If increasing complexity and energy build-up (pressure) cannot be "managed" the organisation will again be pushed to the "edgeof-chaos" and the next cycle of disorder to order commences.

With this theoretical platform in mind, we now briefly consider a recent case of what appears to be an example of nonlinear change in the South African banking sector.

\section{3}

\section{Application of nonlinear change theory to a case organisation (CO)}

During February 2002 Saambou Bank experienced a run on its deposits, which saw approximately ZAR1 billion withdrawn by depositors over a period of 2 days. The sudden onset, rapid unfolding, and the significant scope and consequences of this change process (the "run") fit the profile of nonlinear change - in particular when viewed against the historical stability and success of the bank. At the time of the "run", Saambou Bank had approximately 1600 employees and an asset base of roughly ZAR16 billion. It was considered a mediumsized bank and was ranked the seventh largest bank in the sector. Although its balance sheet was sound, this could not prevent the run and avert the bank's collapse and the state intervened with the appointment of a curator. The latter had to introduce stability in the bank and stem potential contagion in the banking sector (SARB, 2002). On 11 February the bank was suspended on the Johannesburg Stock Exchange and its assets were subsequently sold - marking its permanent demise. This pattern of events suggested the suitability of Saambou Bank as a case organisation.

\subsection{Approach to the study}

The purpose of this paper is to test the applicability of nonlinear change theory (as outlined) in Saambou Bank as a case organisation. It was anticipated that this will further illuminate the dynamics leading up to this dramatic corporate failure and could 
potentially be a useful vantage point on similar seemingly sudden corporate failures. To enable such a test, a valid chronological account of the primary events surrounding and leading up to at least the point of intervention by the State is required as a first step. The timeline so provided could then be matched to the key phases and transitions that constitute the essence of nonlinear change theory, as indicated in Figure 1. This procedure however posed several challenges, which included contending with the time lapse since the collapse of the case organisation in 2002, as well as the methodological concerns that a reliance on respondent memory ${ }^{3}$ raises. Moreover, while it is standard practice for proceedings of meetings to be captured in the minutes, meetings do not occur that frequently (top executives in the case organisation met on a monthly and quarterly basis $^{4}$ ), and dynamics other than those occurring during meetings are seldom documented. Where documentary evidence of company history exists in the case of corporate failures, access to this evidence is often constrained by ongoing investigations into the collapse of these institutions. As a case in point consider that during early 2003 the Receiver at the case organisation forwarded information on alleged breaches of the law by some former directors of the case organisation to the Department of Special Operations of the National Prosecuting Authority (SARB, 2003: 18). Investigations and legal proceedings were still ongoing during $2005 / 2006^{5}$. Indeed, a state of mind that views information dissemination with regard to the case organisation as a matter requiring caution and conservatism was still in evidence at the time of compiling this analysis ${ }^{6}$ and is the result of uncertainty arising from the ongoing investigations into matters concerning the case organisation?

As a result of these complexities the compilation of a chronological account of main events in the case organisation relied on document analysis and a few in-depth interviews. Except for the addition of the interviews, the methodology does not differ from that of, for example, Brown and Jones (2000). In their construction of a baseline of events (a 'narrative') in the "Arms to Iraq
Affair" the researchers analysed various texts which included newspaper reports and government reports. Document analysis in this study entailed some 360 journalistic (newspaper) reports ${ }^{8}$ obtained from three daily and two weekly newspapers for the period December 2000 to January $2003^{9}$, several reports by the South African Reserve Bank (predominantly the Bank Supervision Department), the occasional Government publication (e.g. Government Gazette), some correspondence with and between third parties and the case organisation concerning events at the case organisation (e.g. legal opinions) and several internet-based sources.

While the use of journalistic accounts or news reports is often criticised for being secondary and biased sources, Esterberg (2002: 123-124) argues that these sources are sometimes used by social scientists as primary sources and are particularly useful when investigating changes over time. The issue it seems is how this source is utilised. To control for possible inaccuracies and bias (e.g. sensationalism), the current study focused on common "historical facts" and the frequency of reports concerning the case organisation (a physical counting of the incidence of journalistic reports on the case organisation). To be incorporated in the timeline of the case organisation, events had to be common to several different documentary and interview sources and devoid of discrepancies in terms of the actual event and its factual parameters e.g. who, what, where, when. The process of validating events in the timeline entailed a comparison of salient incidents encountered in journalistic accounts, the various reports issued by the Bank Supervision Department (SA Reserve Bank), various other reports, the text by Mbuya (2002) and the transcribed contents of two in-depth semi-structured interviews that were conducted with high-level 'key informants'. The interviewed respondents had an intimate knowledge of the unfolding dynamics in the case organisation from both internal and external vantage points and, apart from confirming / disconfirming salient moments and dynamics, also provided additional 'rich data'. The interviews employed an interview schedule 
with minimal structure and were audio taped and transcribed for ease of reference. Several members representing depositors and the general public were informally polled to confirm media-reported accounts of the public's perception of the collapse of the case organisation. Financial indicators were confirmed with the aid of data provided by INet Bridge.

\subsection{Chronology of events at the case organisation}

A chronological account of the key events preceding the demise of the case organisation is presented in Table 1. Events are indicated per month except for the period prior to January 2001, and following 11 February 2002. These periods are not of central concern and span longer or indefinite periods of time. Two indicators were used to reveal the most likely nodes where the case organisation, from a nonlinear change theory perspective, may have made the transitions to a subsequent phase in the unfolding nonlinear change process. These were the frequency with which journalistic accounts or reports concerning the case organisation appeared per month, and changes in the share price of the case organisation over time. Share price was reported for the beginning and end of a month, except for the first week of February 2002 for which daily values were reported. When the frequency of journalistic accounts per month revealed a marked change from a previous month (either increased or decreased substantially) and was accompanied by a substantial change in the share price, this was considered meaningful and indicative of an underlying change in the system.

Nonlinear change theory is introduced into the timeline through commentary in column five of Table 1 . These comments suggest specific nonlinear change phases and moments that, in character, appear to fit the cluster of events for the period of time (as indicated in column 1). Alphanumeric symbols A1, B1, C1 to A4, B4 and $\mathrm{C} 3$ refer to specific phases and moments indicated in Figure 1. 


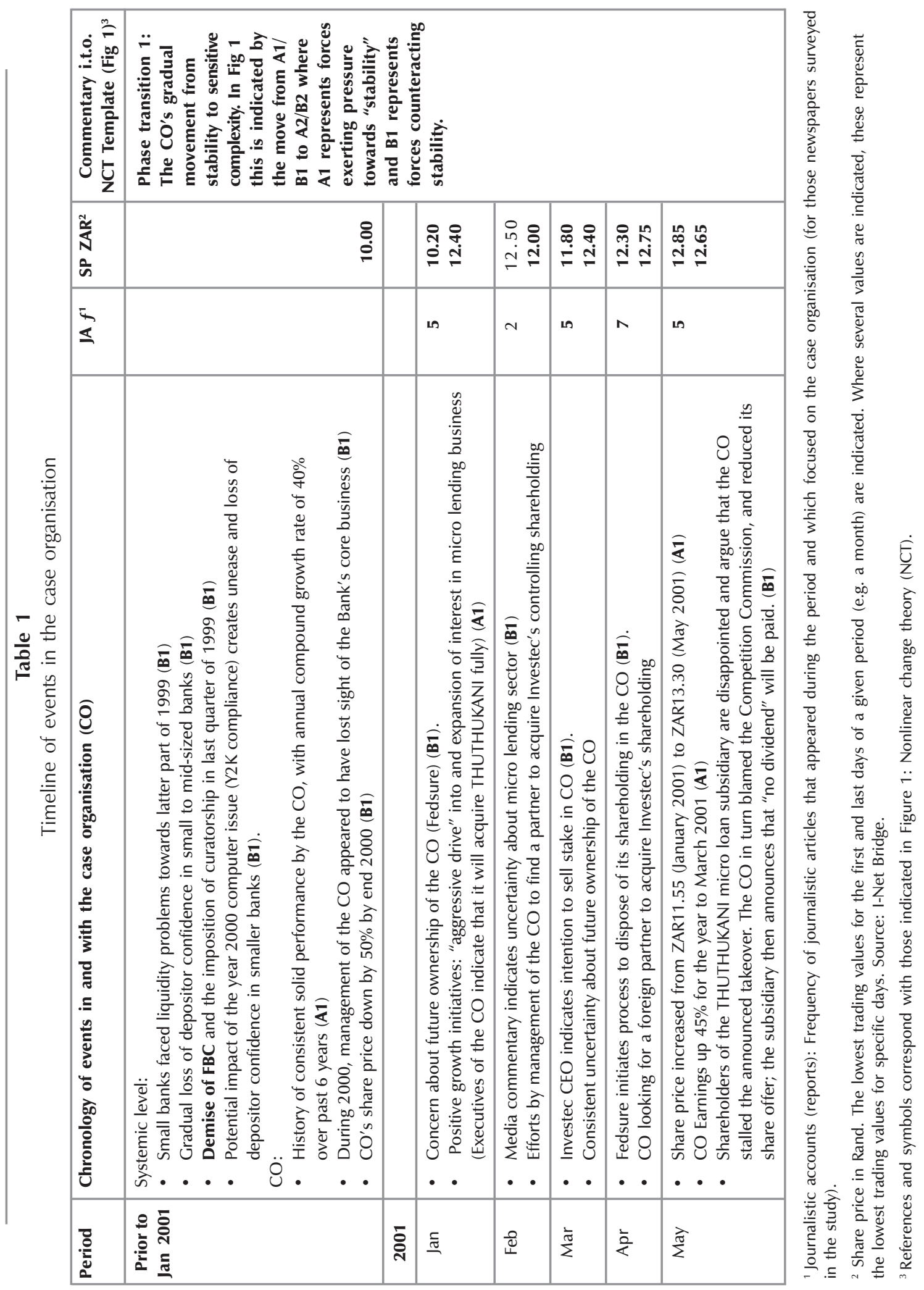




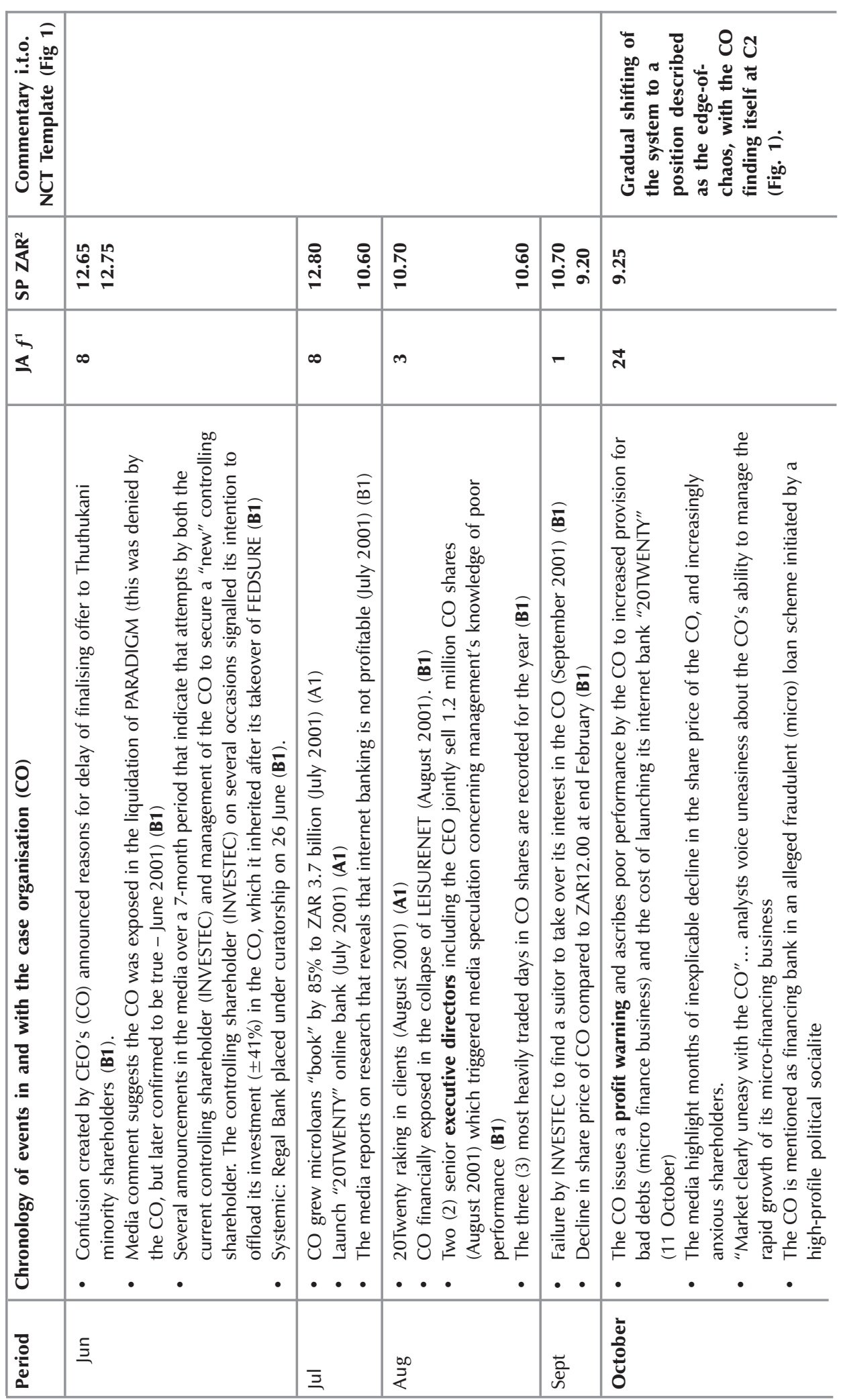




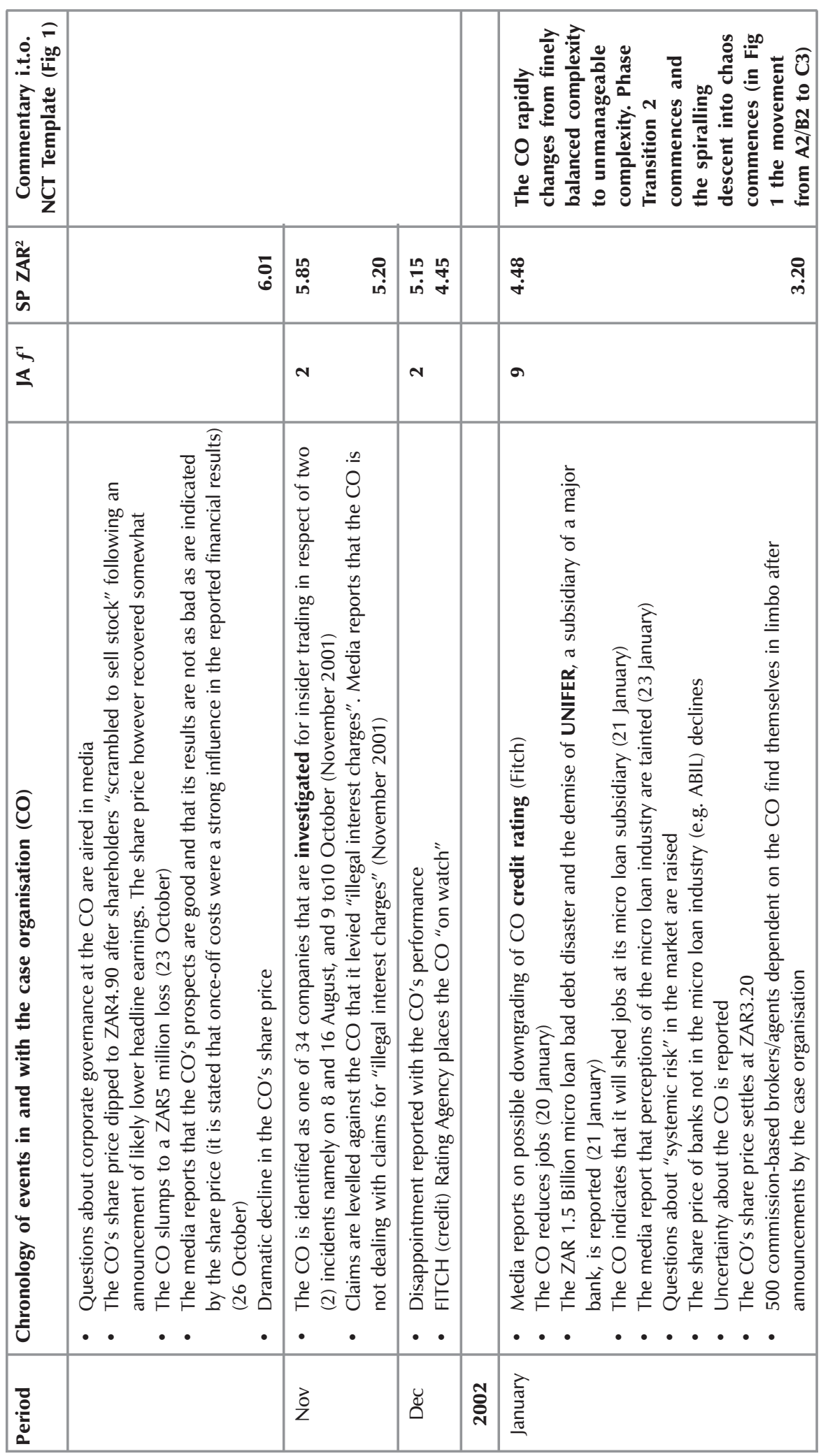




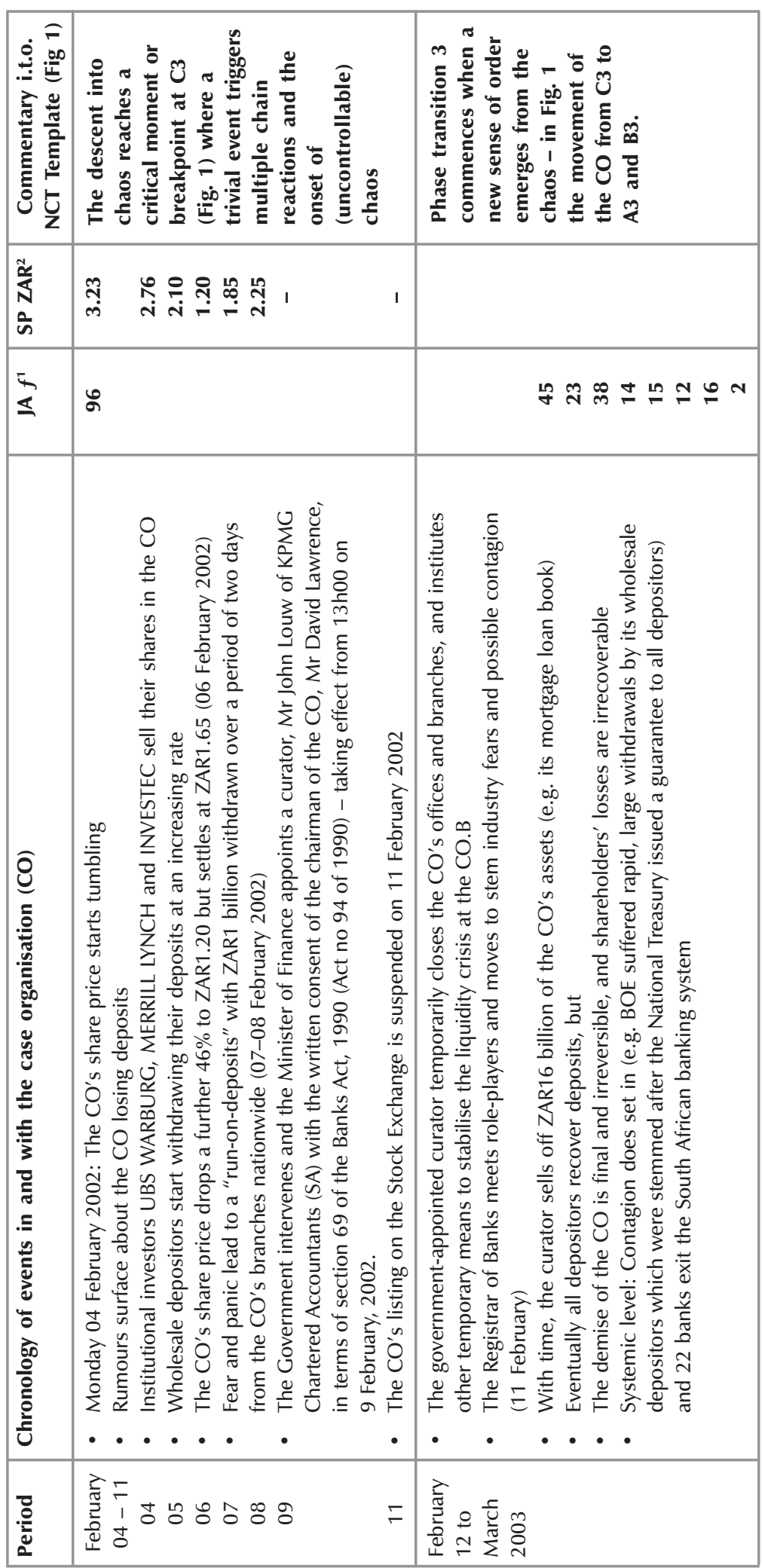




\subsection{The case organisation and nonlinear change theory}

On the basis of major events cited in Table 1 and the two indicators of journalistic accounts and share price, it is argued that the dynamics in the case organisation fit the broad framework of nonlinear change theory. The main characteristics of the different phases in the nonlinear change framework appear to align broadly with events in and with the case organisation.

Phase transition 1: From pre-2001 to the end of September - This phase is characterised by a gradual movement ("shift") of the organisation (system) from relative stability to one of heightened complexity. Stable and manageable relations within the organisation and externally with elements of the broader system and operating environment make way for a situation where the stability of these relations are still maintained, but are potentially at risk because of the many factors to which these relations are linked and which exert influence over these relations. Because these counteracting forces are more or less balanced, the organisation is gradually "pushed" from a situation of low density (or "loose coupling" Weick, 1990) that involves a small number of largely independent organisational elements with limited interaction, to one of high density, which involves a substantial number of interdependent elements and in addition are characterised by high levels of interaction i.e. a greater level of complexity.

Mbuya (2002) argues that the CO, under various names and structures, established a solid success platform over several decades. Against this context the $\mathrm{CO}$ reported substantial increases in short-term earnings and continuing growth initiatives (e.g. the case organisation's microloan book and the launch of its online bank). Evidence of this is noted in positive shifts in the CO's share price from ZAR10.20 (January 2001) to ZAR12.85 (July 2001). However, forces toward stability are offset by events (themes) that emerge during this same period and which run counter to stabilitydriving performance. These included, most importantly, the growing unease arising from the uncertainty about the ownership of the $\mathrm{CO}$, with the controlling shareholder not succeeding in offloading its shareholding despite its public commitment to do so, and the sale of shares by two of the CO's executives. These activities form part of a gradual increase in events that do not fit the paradigm of consistent success and which multiply substantially from May 2001 onwards. This was evidenced among others in a gradual and growing awareness within the $\mathrm{CO}$ (over the period March to May 2001) that fundamental problems existed in the CO's micro financing business (note 4 ).

Shifting towards the edge-of-chaos: From October to the end of December / early January 2002. Although the $\mathrm{CO}$ is still maintaining internal and external relations, these relations are increasingly vulnerable and very unstable. This position (C2) or situation is variously referred to as the "the edge-of-chaos", the "far from equilibrium zone" or the "transition zone". Heightened tension and intricate interdependence among system components and a high degree of interaction among them now characterise the $\mathrm{CO}$, i.e. a very high degree of complexity. This condition or state has been described as "tight coupling"(Perrow, 1984; Weick, 1990) or as a "critical density of interconnectivity" (Price, 2004). System components in this context for example refer to institutions and "agents" such as investors, depositors, analysts, media representatives, $\mathrm{CO}$ executives and employees.

Declining company performance (the issued profit warning in particular), media speculation about inexplicable declines in the share price, uneasiness among analysts and disappointment among stakeholders with the CO's performance, corporate governance issues, and investigations at the $\mathrm{CO}$ for insider trading (two incidents) run counter to stakeholder expectations, prompt uncertainty and diminish confidence.

Phase transition 2: Entering the domain of chaos: Early/mid January to end January 2002 - The noted increase in complexity during the previous stage continues and assumes more critical dimensions during this period. In this state the system (the organisation and its 
context) is exceedingly vulnerable to micro fluctuations in its relations and dynamics and if the $\mathrm{CO}$ can not maintain a state of balance in its relations with all parties within the broader context, a minor event can trigger phase transition 2 and prompt a chaotic change process. The Unifer microloan bad debt disaster (an ABSA subsidiary) which impacted on the banking sector generally but in particular tainted the case organisation (notes 4,7 ) and the Fitch negative rate watch (SARB, 2002: 8) are examples of events that strengthened stakeholder fears and prompted concerns about systemic risk in the market. Developments such as these compounded an already tenuous position and appeared to have "pushed" the $\mathrm{CO}$ to levels of virtually unmanageable complexity (beyond its "threshold of stability" - Byeon, 1999) where the market's eroded confidence and trust in the CO's management was technically beyond managerial control and intensifying. In this regard the Bank Supervision Department argues that a sudden loss of confidence in an institution can be substantially damaging and prompt contagion (SARB, 2001: 9). The sensitively complex nature of this stage is also indicated by the need for financial institutions and the regulator "... to react with speed" (cf. SARB, 2004b: 30) in order to lessen systemic risk.

The onset of chaos proper: The beginning of February (04 February) to 11 February Unmanageable complexity creates a breakpoint at C3 where an insignificant activity (what Perrow, 1984, refers to as a trivial event) triggers the system's descent into chaos. Multiple chain reactions ("multiple failures" - see Perrow, 1984) are set in motion by this trigger event and the situation rapidly spirals out of control, to the point that the organisation is submerged in chaos. This dynamic was revealed by the actions of wholesale depositors who started withdrawing their deposits and institutional investors offloading their shareholding at increasing pace. Rumours about the loss of deposits sent the CO's share price spiralling downwards and prompted the onset of the "runon-deposits" and the withdrawal of approximately ZAR1 billion from branches of the $\mathrm{CO}$ over a period of two days ( 7 and 8 February).

It is interesting to note that some have argued that the "run" would have commenced earlier had it not been for term deposits which prevented the immediate outflow of a significant proportion of deposits ... that this effectively deferred the demise of the $\mathrm{CO}$ for a few months (notes 4, 7).

A marked feature of this type of transition in nonlinear change theory (and characteristic of dissipative systems in particular) is the dramatic and most often catastrophic release (outflow) of energy i.e. chaotic change. The pace and scope of withdrawals over a period of two days is consistent with such a dramatic 'flow of energy'. Depending on the outcome of this chaotic change process, the change can be described as either non-fatal chaotic change or fatal chaotic/catastrophic change.

Phase transition 3: From 12 February onwards - A new, higher level of order and stability is established ("emerges") in the system or suprasystem. If the organisation is incapable of making the "leap" to the new level of stability i.e. the system collapsed as a result of the chaotic change, new, higher level order and stability will then only emerge in the suprasystem or meta-aggregate (cf. Marion \& Bacon, 2000) such as an industry or a national or international setting. The ramifications of the "run" were such that contagion did eventually set in, threatening the sixth-largest bank (BOE) and contributing to 22 smaller banks exiting the banking system in the period up to the end of March 2003 (SARB, 2002: 7). In the context of the case organisation this stability emerges from intervention by the State in the form of the appointment of a curator (RSA, 2002) who temporarily closed the CO's offices and branches to stabilise the liquidity crisis. It also included moves by the Registrar of Banks who met with role-players to quell industry fears. In the end however the demise of the $\mathrm{CO}$ was final and, except for depositors who recovered their deposits, the assets were sold of to various financial institutions (SARB, 2003: 18). 


\section{4}

\section{Discussion}

\subsection{Nonlinear change theory and the dynamics in the case organisation}

The analysis of events in the case organisation provides evidence of a different and more extreme type of change that reflects "nonlinearity" on various dimensions, for example the rapidly reducing but unpredictable timeframes within which material developments manifest in the case organisation, the increase in media attention (this study), the decline in the share price $^{10}$, (and price/earnings ratio from October 2000 to January 2002 - cf. Mbuya, 2002: 71) and the consequences of the unfolding change process for example the "run", and the demise of a longstanding institution in the industry.

Nonlinear change theory introduces an extended temporal perspective which appears to facilitate some measure of enhanced sense making of an otherwise undefined mass of events that often go unheeded or are discounted in favour of the dramatic impact of the hereand-now "visual revolution". The use of a nonlinear change framework (Fig. 1) allows greater contextualisation of this "visual revolution". In particular, it suggests how change is accelerated or amplified (Salem, 2002) and how it evolves i.e. "switching" from gradual evolutionary change to more sudden revolutionary change (Van Tonder, 2004c).

While nonlinear change or nonlinear dynamics is described in terms of three or four phases (cf. Bergmann Lichtenstein, 2000; Priesmeyer \& Baik, 1989), three phases are commonly identified, which echo the orderdisorder-order cycle. This is broadly consistent with Stein's (2004) depiction of disasters as consisting of an incubation period, a critical period and the aftermath. The incubation period is described by Stein (2004: 1243) as the "often lengthy period (months, years or decades) during which certain problems are known but not acted upon". This differs from the critical period, which is a relatively brief period of very short duration (a few minutes to a few days) that follows a "triggering event" (Shrivastava, 1992) and which is characterised by the onset of a catastrophe or catastrophic change. Stein (2004: 1244) argues that an understanding of the critical period is vital as the outcome of the potential disaster will depend on how this brief period is managed. This critical period can be approximated to the week of 04 to 08 February during which the run on deposits occurred. During this week repeated meetings were conducted among industry representatives including the Registrar of banks and the controlling shareholder to arrive at a solution that would circumvent the demise of the bank and possible contagion in the broader banking sector (note 4). This, however, did not materialise and suggests instead that earlier intervention may have greater prospects of success when dealing with corporate catastrophes.

The dilemma with the "critical period" or "visual revolution" however is that it tends to engulf the attention span of managers, scientists and the general public to such an extent that the antecedent conditions of the catastrophe are seldom adequately acknowledged and scrutinised. In reality the "visual revolution" merely represents the temporal and metaphorical tip of the iceberg. Stein's (2004) characterisation of the disaster process, however, occurs without the expanded theoretical framework and context offered by nonlinear change theory and complexity theory. As a consequence primary emphasis is placed on the "critical period" at the cost of the gradual and largely "invisible" unfolding of the potential disaster (or chaotic/catastrophic change process). It is in this regard that nonlinear change theory's emphasis on the development of systemic complexity and hence the process prior to Stein's "critical period" is bound to be of particular value. It suggests that early detection of energy build-up within a case organisation and/or between the case organisation and its context may prove more useful from a disaster containment perspective.

Viewing the events within the case organisation from within an expanded timeframe reveals increasing disharmony between the case 
organisation and its environment (primarily the various stakeholders who define its operating context) to the point of the final "run" and the collapse of the bank. While this portrayal of the events suggests a meta "pattern" of escalation for the 18 months considered in this analysis, nonlinear change theory suggests that the "pattern", i.e. the emergence and gradual development of forces in opposition to the reigning stabilisation forces, will commence substantially before the period considered here. While difficult to demonstrate empirically, some support for this hypothesis is suggested. The Bank Supervision Department of the Reserve Bank (SARB, 2002) for example acknowledges the role of antecedent conditions commencing in 1997 with the South-East Asian financial crisis and its associated banking crisis, the Russian financial crisis of 1998 and, locally, the imposition of curatorship over FBC Fidelity Bank (FBC) in 1999 and more recently, Regal Bank on 26 June 2001 (SARB, 2004a: 18). The invisible pattern wherein the disaster or chaotic change is "set up" some time prior to its visible manifestation has been observed in numerous disasters, for example the Apollo 13 disaster and the Three-Mile Island episode (cf. Perrow, 1984), and has been referred to by Stein (2004) as an "incubation period" (Stein, 2004). From a complex change perspective, the first phase transition, which entails the organisation's conversion to a state of high complexity, appears to offer a somewhat more descriptive and internally coherent account of this "invisible" dynamic and its relation to the next phase (the onset of chaotic change). Marion (1999) argued that it is in fact the prevailing organisational culture, more specifically the network of interdependent events, ideas and people of which it consisted, that are at the root of these invisible dynamics and the subsequent chaos. From this perspective the series of events in the case organisation suggest that a tacit change in management culture may be at the core of the developments in the case organisation. A visible manifestation of this may be the shift in management focus away from the case organisation's core business during 2000 (SARB, 2002: 7). Subsequent managerial actions, during the initial stages of the first phase transition, suggest a greater receptiveness to risk creeping in. This was reflected in, among others, the rapid, successive launch of several growth initiatives, while contending with a substantive ownership issue. The latter stemmed from the controlling shareholder's commitment (initially Fedsure and later Investec) to distance themselves from the case organisation by seeking a buyer for their shareholding. The case organisation's financial exposure to failed business enterprises, the insider trading investigations, unanticipated poor performance and larger than anticipated expenditure (for example the 20Twenty online banking venture) similarly suggest an erosion of the risk management and quality control mindset occurring some time before the actual decision making that led to these incidents (note 7). The context and more specifically the transfer of ownership and the subsequent delay in replacing directors on the Board of the case organisation, for a moment in time created a "corporate governance vacuum" and prompted a perception of it being a "headless chicken" (note 4). This provided further momentum to the underlying change that was already under way. It is possible that this shift was partly facilitated by past success which imbued executives with overconfidence. This, in turn, effectively blinded them to changing realities and operating conditions to the extent that they did not detect the early warning signs (cf. note 4) - an observation consistent with McLarney and Dastrala's (2001) assertion that past success masked Enron Corporation's ability to perceive and respond to similar catastrophic change (the chaotic dynamics of Enron's final days were in fact compared to a "run-on-deposits"- Currall \& Epstein, 2003). However, consistent with Stein's (2004) definition of the incubation period as a period where problems are known but not acted on, there is some indirect evidence (notes 4,7 ) to suggest that one or two key executives may have been aware of underlying problems, e.g. in the personal loans section of the case organisation. However, as argued elsewhere, this level of awareness effectively amounts to non-awareness as a result of the 
cognitive distortions and flawed logic through which individuals deny, minimise or negate indicators of impending problems (Matlin, 1995) or simply deceive themselves (cf. Brown \& Jones, 2000). This in itself is consistent with the typical dynamics and features of the "blindness" stage of organisational decline (cf. Van Tonder, 2004c: 32).

In summary, the application of a nonlinear change framework (theory) to the sequence of events in the case organisation has the advantage of introducing an extended timeframe, which, from this perspective, renders the developments at the case organisation more intelligible. It is consequently possible to recast events and develop plausible hypotheses about the unfolding and amplification of change within the case organisation.

\subsection{Nonlinear change theory and central themes emerging from the case organisation}

From the analysis it emerged that several highly interdependent and interactive variables assumed an important role during the various phase-transitions in the case organisation. These were management (action), the organisation's performance, stakeholders (i.e. the system which comprises industry representatives, analysts, investors, depositors, the regulator's office, media representatives), communication with and amongst stakeholders (both within and outside the organisation), and the role of the media. Consistent with Thiétart and Forgues' (1995) suggestion that complexity in organisations develops when the minimum threshold of three or more variables is highly interdependent and interacts on a consistent basis, these variables suggest the likelihood of increasing complexity.

Prior to the onset of nonlinear dynamics in the case organisation these variables were "loosely coupled" (Weick, 1995) with a fair amount of "slack" or room for variation without adversely impacting one another. However, during the first phase transition they became substantially more "tightly coupled" and lost some of the latitude for variation and tolerating "errors". At the same time this interdependent network of variables and relationships rapidly expanded to embrace more stakeholders. These dynamics, by definition, constitute increasing complexity.

A somewhat reductionistic rendition of these dynamics will suggest that changes in management action - perceived as out-ofcharacter when compared with a historically established management approach, and communicated inter alia via the media, introduced uncertainty among external stakeholders such as investors, analysts, and depositors, and destabilised long-held (favourable) perceptions of the case organisation, its management and its performance. A decision to aggressively pursue the micro financing business while public and media commentary convey scepticism will prompt confusion among stakeholders. These dynamics are substantially compounded when the case organisation subsequently issues a profit warning and ascribes poor financial performance to bad debts in the micro financing business and the costs of the online banking venture (both endeavours being indicative of management judgement and decision making). When portrayed in this manner an erosion of stakeholder confidence and trust in the case organisation and its management is inevitable. Confidence, in turn, is the essence on which the fundamentals of banking are premised and the key to systemic risk or otherwise (SARB, 2001: 9; 2002: 9; notes 4, 7). A loss of confidence and the accompanying uncertainty will prompt information needs among stakeholders which need to be addressed in a convincing manner by management. If attempts at quelling stakeholder uncertainty do not succeed, communication within the network of stakeholders is intensified - and will find further expression in a variety of media including the press which will further fuel (amplify) the concerns of depositors and investors ${ }^{11}$. From a nonlinear change theory perspective it is suggested that the sequence of events at the case organisation, premised on growing uncertainty and a loss of confidence among stakeholders, continually reinforced and amplified a negative "market sentiment"12 (stakeholders) - to a point 
where, eventually, interventions by the case organisation (e.g. press releases, management briefings to analysts and the investor community, etc.) did not succeed in their intentions. "Market sentiment" eventually exceeded a critical threshold whereafter emotion (e.g. uncertainty, anxiety, fear) naturally translated into action that was reflected in a continually declining share price, intensified reporting in the media, institutional investors relinquishing their shareholding and wholesale depositors withdrawing their funds in an exponentially increasing and spiralling fashion. The magnitude of depositor withdrawals over a period of two days (the "runon-deposits") created major liquidity problems for the bank (cf. SARB, 2002) and prompted intervention by the State, which marked the initial stages of the bank's ultimate demise.

The analysis demonstrated the fickle nature of "market sentiment" and the speed and relative ease with which stakeholders as a collective can be pushed to a level of heightened awareness and to the point of acting in unison. During this process the (printed) media performed a ubiquitous but undetected critical role both as conduit for relaying information and (unintentionally) as a catalyst ...by linking, activating and reinforcing links between stakeholders ${ }^{13}$. Supported by information and telecommunications technology the media facilitated the growing interconnectedness of the organisation with its context and accelerated the case organisation's progression towards greater complexity. As such the media was instrumental in the onset of chaotic change (cf. Evans, O'Malley Hammersley \& Robertson, 2001 on the role of communication during crisis) but also in the emergent order following in the wake of the change - a point also argued in the economic literature (cf. Smith, 2001).

At its core the organisation as a complex adaptive social system is comprised of individuals who present with idiosyncratic beliefs and emotions. At the same time it is an integral part of the larger social collective (the suprasystem). Emotion knows no boundaries and is central to all human action wherein it exerts a consistent and powerful influence.
Moreover, "organisations" and "operating contexts" do not experience emotion, but people do, and it is emotion that generates action (Van Tonder, 2004c). "Herding" or swarming behaviour, as evidenced for example in the phenomenon of "market sentiment" that changes rapidly on the basis of speculation and spreads even more rapidly through "contagion" (Staw \& Sutton, 1993), is an emotion-informed phenomenon which was at the core of the "runon-deposits" in this case study. Emotion was similarly prominent during the unfolding events at the case organisation and uncertainty, fear, anxiety, anger, and panic were regularly reported by the media. This is consistent with the high frequency with which emotion terminology has been encountered in economic and financial journals reporting on similar crises (cf. Demirguc-Kunt \& Detriagiache, 1998; Eisenbeis, 1997; Miller, 2003; Ortiz, 2002). "Panic" is most commonly observed, followed by terms such as dissatisfaction, distrust, confidence, fear, and shock. It is here, in the domain of individual and eventually collective emotion, where the forces for instability both within and outside the case organisation originated. In essence, individual emotion was reinforced and amplified to the point of being perceived as an intense collective threat and resulting in aggregate (collective) affective states that are exceptionally powerful and result in dramatic consequences (Staw \& Sutton, 1993) such as the "run-on-deposits".

\section{5}

\section{Implications in brief}

As the substantial number of natural and some not-so-natural catastrophes would suggest, nonlinear change is not a novel phenomenon. In complex adaptive social systems this phenomenon is more uncommon but becoming more salient. As such it may reflect a global drift towards increasing complexity, brought about by population growth, increasingly integrated economies and increasingly global trade and travel, and rapid advances in the domains of information and communications technology. When viewed against this 
dynamically evolving operating context the demise of the case organisation and other similar prominent examples again offer support for the maxim that past success recipes will not hold for the present or the future. Indeed, it is quite possible that institutions with an enduring success history may be predisposed towards nonlinear change.

As yet, however, none of the catastrophic changes that befell, for example, Saambou Bank, Barings Bank and Enron Corporation could be anticipated, and it is only through retrospective analysis of this nature that underlying patterns in seemingly random behaviour could be established. The advent of nonlinear change will seldom if ever afford management the opportunity to engage in retrospective reflection and learning - simply as the organisation may not survive the uncontrollable and irreversible nature of chaotic and catastrophic nonlinear change. This will preclude attempts at dealing with change that are structured around trialand-error or pilot implementation approaches. The dynamics in the case organisation and identified with the aid of nonlinear change theory, ceteris paribus, suggest an approach premised on early detection and prevention rather than cure. The objective should be one of avoidance or minimisation rather than "management" of nonlinear change. This, however, hinges on early detection of vital indicators of the system's evolution towards a state of complexity i.e. substantially before the "visible revolution" is imminent.

Early detection of vital indicators ("warning signs") implies a sensitivity to perceive and respond to hardly noticeable changes and suggests a managerial and organisational sensing capability ("sensors") - referred to as a form of "hyper vigilance" (Van Tonder, 2004d). The metaphor of a seismograph that is used for the early detection of volcanic activity suggests the type and nature of the needed capability. This is of course consistent with the views of the Bank Supervision Department (SARB, 2003: 17) that has emphasised the constant need for vigilance in banks, in order to detect warning signs. Recent examples of nonlinear change in organisations suggest that traditional functions typically responsible for scanning the operating context, "sensing" and information gathering such as executives and directors, auditors, corporate governance officers, corporate advisers, strategists, researchers, analysts, consultants are not capable of discerning early warning signs. Cultivating a sensing capability of this nature is not limited to the traditional means of creating capability (e.g. changes to structures, functions, strategies, policies and procedures, and staffing). Rather, a philosophy but also the practice of organisational learning may prove more effective. The challenge however is one of engaging the organisation in collective information gathering, collective interpretation and sense making, and collective action (cf. Dixon, 1999).

Hyper vigilance is of course not called for on a continuous basis, but will be dictated by the organisation's (systemic) status. Essentially a level of managerial and organisational vigilance is called for that is appropriate to the organisation's mode of functioning e.g. when the organisation shifts from an open systems status to early stages of increasing complexity, a commensurate shift from vigilant to hyper vigilant functioning is indicated. However, if the system is clearly stable, the energy and system resources required for hyper vigilance can be preserved for utilisation in other, more productive pursuits.

Although the extant knowledge on how complexity manifests over time in organisations, is limited and the signs of increasing complexity are therefore somewhat obscure, some avenues are suggested by the analysis of the case organisation. The conscious and systematic monitoring of the frequency and content of the public discourse (e.g. the media, industry events) specifically on company-related issues may prove useful. When this information is supplemented with information on financial indicators known for their susceptibility to market sentiment (e.g. the PE ratio, share price) - in particular "illogical" and dramatic fluctuations - it could serve as a barometer of stakeholder (and "market") sentiment. The use of a nonlinear change framework suggests the adoption of an extended timeframe, which is unlikely to cover a period of less than 24 months. For the latter to be employed effectively, major 
organisational events during this period should be identified, categorised and weighted in terms of their likely influence on the perceptions of stakeholder constituencies. Once again the focus is centrally on events in the public eye and how they are construed and presented. The media should consequently be regarded as a key source of information and in particular as platform for anticipating likely changes in market sentiment.

Energy flow is similarly an important focus of monitoring actions. In this context energy is viewed broadly as "resources" i.e. that which facilitates any form of "movement" and includes the movement of capital/funds, equipment, information and in particular employee energy - a manifestation of employee/ stakeholder emotion. The direction and intensity of energy flow as well as changes or fluctuations and the constraints on energy flow (e.g. deviations, bottlenecks/ build-ups) will suggest critical pressure points. If energy buildup is left unattended, these could push the system to greater levels of complexity and a change in the systems status. The management of employee emotion is a particularly sensitive and important consideration as emotion has traditionally been negated in both the theory and practice of organisational management. As the analysis suggested, emotion performs a pervasive role and proves to be an important variable in the eventual demise of the case organisation. For this reason managerial practice that attends adequately to employee emotion, supported by specific mechanisms to detect and contain emotional upheaval also through effective media communication, will prove beneficial.

Initiatives aimed at early detection will benefit from regular, credible audits of organisational climate, culture in particular, governance practices, and employee and stakeholder sentiment. Regular monitoring of stakeholder sentiment is needed to detect similar changes (shifts) in the awareness levels of the larger social collective. In the case organisation the perceptiveness of the social collective was underestimated and its potential for coherent action remained largely undetected, which reaffirmed the importance of truthful, effective and transparent relations with stakeholders.

Management action, logically should and in practice did perform a critical role in the compromised organisation-environment relationship and the case organisation's turn towards catastrophe. To circumvent chaotic change, the identification and appointment of managerial staff need to advance to a finer level of discrimination and sophistication, where the inclination towards risk, learning and reinvention, social and environmental perceptiveness, and business ethics and value structures are examined in greater detail. The appointment and / or promotion of key staff partially constitute those "initial conditions" on which the organisation's survival may later depend - in particular when the organisation is characterised by a high degree of complexity and enters the domain referred to as the edgeof-chaos and where chaotic change is highly probable. Understandably managerial mindsets are a critical focal area during times of complex change (Smith \& Saint-Onge, 1996) and more specifically the receptiveness of managers to the widest possible range of perspectives (McGill, Slocum \& Lei, 1992). This requirement is consistent with the view that the managerial task assumes a different, non-traditional and more of a "sense making" character the moment managers recognise the complex adaptive nature of their systems (Ashmos, Duchon \& McDaniel, 2000). Research, investigating disasters such as the Apollo 13 and Three-Mile Island nuclear disaster (Perrow, 1984; Stein, 2004), the Tenerife Air disaster (Weick, 1990) and several others, suggests that the absence of appropriate action during unfolding disasters relates to inappropriate sense making. Tacit interpretive frameworks (schemata) and inaccuracies in personal logic (cognitive distortions - Matlin 1995) result in systematic and recurring processing errors and misinterpretation (Van Tonder, 2004c) which prevent appropriate detection of "early warning signs" during an unfolding disaster (the often reported "blindness" of executives). Warning signs are often noticed but not acted on by those 
concerned (Choo, 2005) and it is in this regard that induction into complexity theory and nonlinear change theory may have further utility value. Implicit in the preceding views is the requirement of a strong management disposition towards learning, but as previously argued (Van Tonder, 2004d), this needs to be supported with an appropriate knowledge base and understanding of general systems and complex adaptive systems theory, as well as the potential role of incremental developments and changes within a broader systemic "field". A systematic movement of the organisation's culture to one of collective (organisational) observation, sense making, and action in response to a multitude of often seemingly irrelevant environmental cues is necessary for the early detection of complex system dynamics. Early detection, in turn, should facilitate a measure of preparation, for example, in the form of capacity development for extreme change, and ensure focused pre-emptive intervention at emerging tension points where energy may build up in the system.

\section{6}

\section{Concluding perspectives}

The absence of suitable theoretical and methodological frameworks is a primary factor that prevents managers from recognising emergent phenomena (Goldstein, 1999). It is in this regard that the notion of nonlinear change offers a useful behavioural framework for viewing and interpreting organisational dynamics over an extended period of time. At the same time it also provides a detailed and logical account of dramatic, sudden and irreversible organisational change at a systemic level. The enduring challenge of unravelling the causes and nature of the organisation's transition between qualitatively different types of organisational change (e.g. from evolutionary to revolutionary change, or Type I to Type II change) still remains, as the precise chain of cause-and-effect relationships at micro scale that translates into chaotic and catastrophic nonlinear organisational change is still not readily discernible. Indeed, the application of nonlinear change theory in this analysis does not suggest that specific causes for the demise of the case organisation be considered. The application of the theory instead sensitises the reader to the inextricably intertwined role of context and the dynamics within the case organisation and how the latter cannot be considered to the exclusion of the less obvious but pervasive presence of system dynamics (dynamics in the market, the banking sector and so forth). Nonlinear change theory, however, further illuminates these transition dynamics and from a meta perspective suggests several indicators which could eliminate some of the "infinite" variance that obscures the causes of nonlinear change. These need to be supplemented, obviously, with more technical operational measures for dealing with systemic risk and potential contagion (cf. Kaufman \& Scott, 2003), but as it is implied here, these measures may prove more effective when considered from within the meta framework offered by nonlinear change theory.

The examples of disastrous (nonlinear) change are still relatively few, but the incidence of this form of institutional change appears to be on the increase. While managers and practitioners may be somewhat disinclined to consider this a material possibility in day-today organisational functioning, the unexpected demise of the case organisation and others such as Barings, Enron, Parmalat, and Worldcom bear testimony to the presence of such change. However, nonlinear change may be a more probable reality than executives are capable of detecting or may wish to admit. In this vein Rosser (2002: 449) has argued that ... "Recognizing the existence of nonlinear feedback effects through technology, complementarity of policies and institutions, and the interactions between people in their attitudes and expectations during periods of major systemic change means that the possibility of sudden large changes arising from apparently small influences must be taken into account."

In the final analysis nonlinear change may not be circumvented but an informed and alert management could minimise the potentially catastrophic consequences when circumstances suggest the possibility of such change. 


\section{Endnotes}

1 For a considered review of a significant number of these change typologies, consult Van Tonder (2004c).

2 Type I change is described as a steady-state incremental or step-by-step sequential change which evolves over an extended period of time, does not have a disruptive influence on the system and is generally perceived to be within the control of the system (Van Tonder, 2004c: 234).

3 A substantial research base is in existence, which indicates that memory and hence the act of remembering is influenced by natural decay, interference, repression, and distortion (cf. Bruning, Schraw \& Ronning, 1999; Leahey \& Harris, 2001). Adult (personal) memory is in fact substantially less accurate than a person's belief and estimation of his/her memory capability (Johnson, Hastroudi \& Lindsay, 1993). Indeed memory disturbance, amnesia and or selective bias in recalling and retrieving key moments of an event that was experienced as traumatic or difficult, are well documented in the psychological literature (cf. Harvey \& Herman, 1994; Herman, 1995; Van der Kolk, 1994). This was for example stated in as many words by respondent 1 who confirmed that the experience of the immediate period leading up to (at that stage) the probable demise of the bank was traumatic, very stressful and comparable to being on "death row". As it turned out the respondent did not indicate specific dates of occurrences but could broadly indicate weeks or months (e.g. the first week of..., or a meeting at the end of a specific month ...).

4 Information provided by 'key informant'/ respondent 1.

5 See for example Rose, R. (2005) "Bosses in court over Saambou collapse", Business Day, 15 September, 2005: 1. Editorial (2005) "Dirty white collars", Business Day, Opinion \& Analysis, 16 September 2005: 10. Data obtained from respondents 1 and 2 .

6 Requests for interviews were not responded to by, among other, the SA Reserve Bank. Moreover, respondents alluded to the improbability of potential sources of information (stakeholders) agreeing to interviews, the responsibilities of the Curator w.r.t. information dissemination, and the influence of the Access to information Act.

7 Information provided by 'key informant' 2 .

8 These reports covered incidents/events concerning the case organisation and which were deemed by editorial staff to be of sufficient significance to draw public attention to these eventualities and hence warranted reporting. In one sense journalistic accounts are also reflective of stakeholder needs and sentiments. For example: A reader may be concerned with the prevailing levels of crime and consequently seek out accounts in the press that address crime. Feedback received through correspondents and other sources prompts the editor to insert more reports on crime in subsequent editions. The same argument applies to readers who were depositors or had some relation with the case organisation. Intensified coverage (focus) on the case organisation in the press, from this perspective to an extent also conveys the focus of part of the readership (the larger systemic context of the case organisation). Moreover, these reports unavoidably mediate public perception in respect of the case organisation, regardless of the authenticity and accuracy of reporting. It constitutes a crucial communication and influence channel and is therefore a source of information that should be factored into management perspectives.

9 Business Day, Beeld, Mail \& Guardian, Sunday Times, Rapport.

10 Viewed in particular from an expanded perspective (beyond the timeframe indicated in Table 1). Mbuya (2002: 72) for example considers the share price from the beginning of 1999 to suspension on 11 February 2002. From this perspective a markedly sudden decline, consistent with the concept of nonlinearity is observed.

11 To adequately comprehend the situation in which the case organisation and its management found itself, cognisance should be taken of the defining parameters of complexity ("descriptive complexity") - defined earlier as 1) a significant number of variables within a setting or "field", 2) a high degree of interdependence between them, as well as 3) a high frequency of interaction among these variables. Accordingly, interactive communication networks among stakeholders have rapidly expanded e.g. concerned depositors and investors who may have been residing in the background would now engage analysts, management, co-investors, journalists and any other source that could possibly shed light on developments at the case organisation and the "safety" of their interests (that is, mitigate their anxieties and fears). If the response does not reduce the enquirer's fears, it amplifies these fears and facilitates an escalation in interaction. 
12 See for example the micro processes of nonlinear change i.e. autocatalysis and resonance (Van Tonder, 2004c: 139-141)

13 Every journalistic account forms a part of interaction and communication patterns within the overarching system but is merely an element (the metaphorical tip of the iceberg) in a web of otherwise multiple, intricate cause-and-effect relationships

- among events within the case organisation and elements of its operating context,

- interactions among various internal and external stakeholders, and

- overall systemic interaction with its interfaces with media activity itself.

Precise causal triggers and cause-and-effect relations within this web of interactive relationships are impossible to isolate and are characteristic of an evolving and increasingly complex organisation-environment system with emergent phenomena being the net consequence (cf. Goldstein, 1999 on the criteria of emergent phenomena and the notion of descriptive complexity).

\section{References}

1 APPLEBAUM, S.H., \& WOHL, L. (2000) "Transformation or change: Some prescriptions for health care organizations", Managing Service Quality, 10(5): 279-298.

2 ASHMOS, D.P. DUCHON, D., \& MCDANIEL, R.R. (2000) "Organizational responses to complexity: The effect on organizational performance", Journal of Organizational Change Management, 13(6): 577-594.

3 BAMFORD, D.R. \& FORRESTER, P.L. (2003) "Managing planned and emergent change within an operations management environment", International Journal of Operations \& Production Management, 23(5): 546-564.

4 BARTUNEK, J.M. (1993) "The multiple cognitions and conflicts associated with second order organizational change" In J.K. Murnighan (ed.), Social psychology in organizations: Advances in theory and research, Prentice Hall: Englewood Cliffs, NJ.

5 BARTUNEK, J.M. \& MOCH, M.K. (1987) "First-order, Second-order, and Third-order change and organizational development interventions: A cognitive approach", Journal of Applied Behavioral Science, 23(4): 483-500.
6 BEER, M. \& NOHRIA, N. (2000) "Cracking the code of change", Harvard Business Review, MayJune, 133-141.

7 BERGMANN LICHTENSTEIN, B.M. (2000)

"Emergence as a process of self-organizing: New assumptions and insights from the study of nonlinear dynamic systems", Journal of Organizational Change Management, 13(6): 526544.

8 BEESON, I. \& DAVIS, C. (2000) "Emergence and accomplishment in organizational change", Journal of Organizational Change Management, 13(2): 178-189.

9 BROWN, A.D. \& JONES, M. (2000)

"Honourable members and dishonourable deeds: Sensemaking, impression management and legitimation in the 'Arms to Iraq Affair"', Human Relations, 53(5): 655-689.

10 BOLTON, M. \& HEAP, J. (2002) "The myth of continuous improvement", Work Study, 51(6): 309-13.

11 BRUNING, R.H. SCHRAW, G.J., \& RONNING, R.R. (1999) Cognitive Psychology and its Instruction ( $3^{\text {rd }}$ ed.) Prentice Hall: Upper Saddle River, NJ.

12 BURNES, B. (2003) "Managing change and changing managers from ABC to XYZ", Journal of Management Development, 22(7): 627-642.

13 BYEON, J.H. (1999) "Non-equilibrium thermodynamic approach to change in political systems", Systems Research and Behavioral Science, 16(3): 283-291.

14 CHOO, C.W. (2005) "Information failures and organizational disasters", MIT Sloan Management Review, Spring 2005, 46(3): 8-10.

15 COLLINS, D. (1996) "New Paradigms for change? Theories of organization and the organization of theories", Journal of Organizational Change Management, 9(4): 9-23.

16 CURRALL, S.C. \& EPSTEIN, M.J. (2003) "The fragility of organizational trust: Lessons from the rise and fall of Enron”, Organizational Dynamics, 32(2): 193-206.

17 DEMIRGUC-KUNT, A. \& DETRIAGIACHE, E. (1998) "The determinants of banking crises in developing and developed countries", IMF Staff Papers, 45: 81-109.

18 DIXON, N.M. (1999) The Organizational Learning Cycle: How We Can Learn Collectively ( $2^{\text {nd }}$ ed.) Gower: Hampshire.

19 DOOLEY, K.J. \& VAN DE VEN, A.H. (1999) "Explaining complex organizational dynamics", Organization Science, 10(3): 358-372. 
20 ESTERBERG, K.G. (2002) Qualitative Methods in Social Research, McGraw-Hill: Boston, MA.

21 EVANS, C., O'MALLEY HAMMERSLEY, G. \& ROBERTSON, M. (2001) "Assessing the role and efficacy of communication strategies in times of crisis", Journal of European Industrial Training, 25(6): 297-309.

22 GERSICK, C.J.G. (1991) "Revolutionary change theories: A multilevel exploration of the punctuated equilibrium paradigm", Academy of Management Review, 16(1): 10-36

23 GOERNER, S.J. (1995) "Chaos, evolution, and deep ecology", In R. Robertson and S. Combs (eds.) Chaos Theory in Psychology and the Life Sciences, Lawrence Erlbaum Associates: Mahwah, New Jersey.

24 GOLDSTEIN, J. (1999) "Emergence as a construct: History and issues", Emergence, 1(1): 49-72.

25 GOLEMBIEWSKI, R.T., BILLINGSLEY, K. \& YEAGER, S. (1976) "Measuring change and persistence in human affairs: Types of change generated by O.D. designs", Journal of Applied Behavioral Science, 12: 133-154.

26 GREINER, L.E. (1972) "Evolution and revolution as organizations grow", Harvard Business Review, 50 (4): 37-46.

27 GREINER, L.E. (1998) "Evolution and revolution as organizations grow", Harvard Business Review, May-June: 55-67.

28 GRINT, K. (1998) "Determining the indeterminacies of change leadership", Management Decision, 36(8): 503-508.

29 HARVEY, M.R. \& HERMAN, J.L. (1994) "Amnesia, partial amnesia, and delayed recall among adult survivors of childhood trauma", Consciousness and Cognition, 4: 295-306.

30 HERMAN, J.L. (1995) "Crime and memory", Bulletin of the American Academy of Psychiatry and the Law, 23: 5-17.

31 JOHNSON, M.K., HASTROUDI, S. \& LINDSAY, D.S. (1993) "Source monitoring", Psychological Bulletin, 114: 3-28.

32 KAUFMAN, G.G. \& SCOTT, K.E. (2003)

"What is systemic risk, and do bank regulators retard or contribute to it?", The Independent Review, VII(3): 371-391.

33 LEAHEY, T.H. \& HARRIS, R.J. (2001) Learning and cognition ( $5^{\text {th }}$ ed.) Prentice Hall: Upper Saddle River, New Jersey.

34 LEVY, A. \& MERRY, U. (1986) Organisational Transformation: Approaches, Strategies, Theories, Praeger: New York, NY.
35 LEWIN, K. (1951) Field Theory in Social Science, Harper \& Row: New York, NY.

36 MAGUIRE, S. \& MCKELVEY, B. (1999) "Complexity and management: Moving from fad to firm foundations", Emergence, 1(2): 19-61.

37 MARION, R. (1999) The Edge of Organization, Sage: Thousand Oaks, California.

38 MARION, R., \& BACON, J. (2000)

"Organizational extinction and complex systems", Emergence, 1(4): 71-96.

39 MARIOTTI, J. (1998) "10 Steps to positive change", Industry Week, 247(14): 82.

40 MATLIN, M.W. (1995) Psychology (2 ${ }^{\text {nd }}$ ed.) Brace College: Fort Worth, TX.

41 MBUYA, J.C. (2002) The Rise and Fall of Saambou Bank, Sunnyprint: Pretoria.

42 MCGILL, M.E., SLOCUM, J.W. \& LEI, D. (1992) "Management practices in learning organizations", Organizational Dynamics, 21: 4-17.

43 MCLARNEY, C. \& DASTRALA, R. (2001) "Socio-political structures as determinants of global success: The case of Enron Corporation”, International Journal of Social Economics, 28(4): 349-367.

44 MILLER, V. (2003) "Bank runs and currency peg credibility", Journal of International Money and Finance, 22: 385-392.

45 MOURIER, P. \& SMITH, M. (2001) Conquering Organizational Change: How to Succeed where Most Companies Fail, CEP Press: Atlanta.

46 NORTIER, F. (1995) "A new angle on coping with change: Managing transition!", Journal of Management Development, 14(4): 32-46.

47 ORTIZ, G. (2002) "Recent emerging market crises: What have we learned?", The Per Jacobsson Lectures, The Per Jacobsson Foundation: Basil.

48 PASCALE, R.T. (1999) "Surfing the edge of chaos", Sloan Management Review, Spring: 8394.

49 PERROW, C. (1984) Normal Accidents: Living with High-Risk Technologies, Basic Books: New York, NY.

50 PRICE, I. (2004) "Complexity, complicatedness and complexity: A new science behind organizational intervention", Emergence: Complexity \& Organization, 6(1-2): 40-48.

51 PRIESMEYER, H.R. \& BAIK, K. (1989) "Discovering the patterns of chaos", Planning Review, 17(6): 14-21, 47.

52 PRIGOGENE, I. \& STENGERS, I. (1984) Order Out of Chaos: Man's New Dialogue with Nature, Bantam Books: Toronto. 
53 RSA (REPUBLIC OF SOUTH AFRICA) (2002) Government Gazette, 11 February, 440(23121) Pretoria.

54 ROSSER, M.V. (2002) "Experiences of economic transition in complex contexts", International Journal of Social Economics, 29(6): 436-452.

55 SALEM, P. (2002) "Assessment, change, and complexity”, Management Communication Quarterly, 15(3): 442-450.

56 SARB (SOUTH AFRICAN RESERVE BANK) (2001) Annual Report 2001, Bank Supervision Department, RP10/2002, Pretoria.

57 SARB (SOUTH AFRICAN RESERVE BANK) (2002) Annual Report 2002, Bank Supervision Department, RP13/2003, Pretoria.

58 SARB (SOUTH AFRICAN RESERVE BANK) (2003) Annual Report 2003, Bank Supervision Department, RP20/2004, Pretoria.

59 SARB (SOUTH AFRICAN RESERVE BANK) (2004a) Annual Report 2004, Bank Supervision Department, Pretoria. Available at http:// www.reservebank.co.za.

60 SARB (SOUTH AFRICAN RESERVE BANK) (2004b) Financial Stability Review March 2004, Pretoria.

61 SCHABRACQ, M.J. \& COOPER, C.L. (2000) "The changing nature of work and stress", Journal of Managerial Psychology, 15(3): 227 241.

62 SHRIVASTAVA, P. (1992) Bhopal: Anatomy of a crisis ( $2^{\text {nd }}$ ed.) Chapman: London.

63 SMITH, B.D. (2001) "Banks, short-term debt and financial crises: Theory, policy implications, and applications: A comment", CarnegieRochester Conference Series on Public Policy, 54: 73-83.

64 SMITH, P.A.C. \& SAINT-ONGE, H. (1996) "The evolutionary organization: Avoiding a Titanic fate", The Learning Organization, 3(4): 4-21.

65 STAW, B.M. \& SUTTON, R.I. (1993) "Macro organizational psychology". In J.K. Murnighan (ed.) Social Psychology in Organizations: Advances in Theory and Research, Prentice Hall: Englewood Cliffs, New Jersey.

66 STEIN, M. (2004) "The critical period of disasters: Insights from sense-making and psychoanalytic theory" Human Relations, 57(10): 1243-1261.

67 STYHRE, A. (2002) "Nonlinear change in organizations; Organization change management informed by complexity theory", Leadership \& Organization Development Journal, 23(6): 343-51.
68 SULLIVAN, T.J. (1999) "Leading people in a chaotic world", Journal of Educational Administration, 37(5): 408-423.

69 THIÉTART, R.A. \& FORGUES, B. (1995) "Chaos theory and organization", Organization Science, 6(1): 19-31.

70 TUSHMAN, M. \& ROMANELLI, E. (1985) "Organizational evolution: A metamorphosis model of convergence and reorientation”, In L.L. Cummings, \& B.M. Staw (eds.) Research in Organizational Behavior, 7, CT JAI Press: Greenwich.

71 VAKOLA, M., TSAOUSIS, I. \& NIKOLAOU, I. (2004) "The role of emotional intelligence and personality variables on attitudes toward organisational change", Journal of Managerial Psychology, 19(2), 88-110.

72 VAN DER KOLK, B.A. (1994) "The body keeps the score: Memory and the evolving psychobiology of posttraumatic stress", Harvard Review of Psychiatry, 1: 253-65.

73 VAN DE VEN, A.H. \& POOLE, M.S. (1995) "Explaining development and change in organizations", Academy of Management Review, 20(3): 510-540.

74 VAN TONDER, C.L. (1999) "Organisation identity: An exploratory study”, Unpublished doctoral thesis, Rand Afrikaans University: Johannesburg.

75 VAN TONDER, C.L. (2004a) “'Organisational transformation': Wavering on the edge of ambiguity", SA Journal of Industrial Psychology, 30(3): 53-64.

76 VAN TONDER, C.L. (2004b) "The march of time and the "evolution" of change", SA Journal of Industrial Psychology, 30(3): 41-52.

77 VAN TONDER, C.L. (2004c) Organisational Change: Theory and Practice, Van Schaik: Pretoria.

78 VAN TONDER, C.L. (2004d) "Organisations on the edge: Focusing on and exploring the nature of non-linear organisational change", Poster presentation at the International Workshop on Complexity and Philosophy, November 2004, Rio de Janeiro.

79 VAN TONDER, C.L. (2005a) "The unacknowledged contribution of organisational change practice to organisational and employee wellness", Proceedings of the 2005 International Conference on the Changing World of Work, 8-9 March, Vanderbijl Park, South Africa, 102-15.

80 VAN TONDER, C.L. (2005b) "Complex, chaotic and catastrophic: The advent of nonlinear change", Paper delivered at the Fifth. 
International Conference on Knowledge, Culture and Change in Organisations, 19-22 July,

University of the Aegean, Island of Rhodes, Greece.

81 WATZLAWICK, P., WEAKLAND, J.H. \& FISCH, R. (1974) Change: Principles of Problem Formation and Problem Resolution, Norton: New York.
82 WEICK, K.E. (1990) "The vulnerable system: An analysis of the Tenerife Air Disaster", Journal of Management, 16(3): 571-93.

83 WEICK, K.E. (1995) Sensemaking in Organizations, Sage: Thousand Oaks, CA. 